\title{
Assessment of Facial Injury by 'Slock' in Incarcerated Patients
}

\author{
Charles Dodge Rees ${ }^{1}$ BS, Adam Blancher ${ }^{1}$ MD, Paige Bundrick ${ }^{2}$ MD, Mickie Hamiter ${ }^{2}$ MD, Tara Moore-Medlin² and Cherie-Ann O. \\ Nathan ${ }^{2, *}$ MD, FACS \\ ${ }^{1}$ Louisiana State University Health Sciences Center, Shreveport, LA, USA \\ ${ }^{2}$ Department of Otolaryngology-Head and Neck Surgery, Louisiana State University Health Sciences Center, Shreveport, LA, USA
}

${ }^{*}$ Corresponding author: Cherie-Ann O. Nathan, Department of Otolaryngology-Head and Neck Surgery, Louisiana State University Health Sciences Center, Shreveport, LA, USA; Email: cnatha@lsuhsc.ed

Received: October 12, 2020; Accepted: October 20, 2020; Published: October 25, 2020

\begin{abstract}
Objectives: A 'slock' is a padlock in a sock used as an improvised weapon in correctional facilities to induce trauma. Although assault and head injury rates are high in this setting, this is the first study to analyze facial fracture patterns by mechanism of injury. The purpose of this assessment was to examine the seemingly increasing prevalence of 'slock' induced facial fractures and the pattern and degree of injury caused by this device.

Methods: This quality assessment initiative was performed through retrospective analysis of incarcerated patients treated surgically for facial fractures at an academic medical center from 2011-2019. Data collection included the cause of injury, prevalence of padlock induced facial fractures and anatomical locations of fractures.

Results: Over an 8-year period, 435 inmates required surgical treatment for facial fractures. Of those, 366 reported injury by an intentional mechanism. 57 patients $(16 \%)$ described involvement of a padlock and $23(6 \%)$ reported use of a 'slock'. The prevalence of padlock induced facial fractures increased 2-fold from 2012-2017. In 57 patients with a padlock or 'slock' injury, the most common fracture sites involved the mandible (53\%), zygomatic arch (15\%) and the nasal bone $(13 \%)$. An average of $2.28(\mathrm{SD}=1.33)$ fractures per patient occurred with padlocks.
\end{abstract}

Conclusion: A padlock is the most common cause of facial fracture besides a fist. We hope to contribute to better control of the padlock supply available to inmates to reduce the burden and severity of facial trauma. Future aims include analyzing the cost to society for treatment.

Keywords: Slock, Padlock, Lock in a sock, Facial fracture patterns, Improvised weapons

\section{Introduction}

As of 2017, the US incarcerated population comprised 1.5 million people with an adult incarceration rate of 568/100,000 [1]. In 2017, Louisiana had the highest adult incarceration rate of any state at $942 / 100,000$ [2]. In combination with a high incarceration rate, it is thought that prisons are becoming increasingly more violent. The British Ministry of Justice reports over a 2-fold increase in serious assault rates in their incarcerated population from 2008-2018 [3]. The rate of head injury in the incarcerated population is nearly 5 times higher than the general population [4]. In addition, the hospitalization rate is about 10 times higher than that of the general population [4]. The combination of these reports shows the incarcerated population places a large financial burden on society to cover medical costs. The most common injury in this population is mandibular fracture, consisting of $46 \%$ of inmate injuries [5]. Although common, limited literature exists on the mechanisms and patterns of facial trauma. Inmates convert miscellaneous items into weapons, including toothbrushes, disposable razors, batteries, and padlocks [6]. $9 \%$ of all confiscated prison weapons are of the sap-type which is a heavy weight at the end of a flexible handle [6]. A sap-type weapon is used in
$17 \%$ of inmate-on-inmate weapon induced injuries [6], many of which are a 'slock'. A 'slock' is a padlock that is placed in a sock and used as an improvised weapon. Socks are distributed to prisoners and padlocks can be purchased in the prison commissary for inmates to protect their personal items. These two items are easily accessible and can be easily converted to a weapon. Prisons are a controlled environment and preventing inmate access to specific items, including padlocks, could reduce the burden of facial trauma and medical care costs for incarcerated patients. The purpose of this assessment was to examine the seemingly increasing prevalence of 'slock' induced facial fractures and the pattern and degree of injury caused by this ad-hoc device.

\section{Methods}

This quality assessment initiative was performed through retrospective chart review of incarcerated patients. IRB exemption was obtained as a quality improvement study. Selected patients were treated surgically for facial fractures at University Health and Ochsner LSU Health Shreveport Academic Medical Center from 2011-2019. Data collection included patient-reported mechanism of injury, prevalence of padlock induced facial fractures, anatomical locations of fractures induced by a padlock repaired surgically, age at discharge 
and gender. Mechanisms of injury were grouped into unintentional or intentional causes. An unintentional injury was defined as a facial fracture occurring from an accidental cause. Examples include a fall in the shower, sport associated injury, etc. An intentional injury was defined as a mechanism involving an inmate-on-inmate, staff-oninmate, or self-induced injury. Examples include a fist to face injury,

Table 1: Mechanism of intentional injuries.

\begin{tabular}{|c|c|c|}
\hline Mechanism of intentional injuries & Number of injuries $(\mathbf{n}=\mathbf{3 6 6})$ & $\mathbf{\%}$ \\
\hline Fist to face & 200 & $55 \%$ \\
\hline Padlock $^{\dagger}$ & 57 & $16 \%$ \\
\hline Unknown object $^{\text {Other weapons }}{ }^{\ddagger}$ & 14 & $4 \%$ \\
\hline Foot to face & 12 & $3 \%$ \\
\hline Fall following altercation & 8 & $2 \%$ \\
\hline Head to face & 5 & $1 \%$ \\
\hline Brass knuckles & 2 & $1 \%$ \\
\hline Knee to face & 2 & $1 \%$ \\
\hline Elbow to face & 2 & $1 \%$ \\
\hline Altercation with police & 2 & $1 \%$ \\
\hline Undefined assault & 2 & $16 \%$ \\
\hline
\end{tabular}

† 23 of 57 Padlock cases specifically described the use of a 'slock' weapon. ${ }^{\ddagger}$ Other weapons were used only once to induce injury and included items such as a baseball bat, bowl, broom handle, phone, remote control, etc. 'slock' to face, etc. Patients with unintentional and undocumented causes of injury were not further analyzed. Intentional injuries were categorized by specific mechanism. Padlock-induced injuries were classified by anatomical location of fracture and number of fractures per patient. Fracture location data was obtained from the imaging report in the patient chart.

\section{Results}

From 2011-2019, 435 incarcerated patients required surgical treatment for facial fractures. Of those, $366(84 \%)$ patients reported injury by an intentional mechanism and 57 (13\%) reported injury by an unintentional mechanism. As seen in Table 1, 57 patients (16\%) described involvement of a padlock and $23(6 \%)$ reported specified the use of a 'slock.' Padlocks were the second most common cause of facial fracture after the use of a fist, composing of 200 (55\%) of all surgically repaired facial fractures. 60 (16\%) fractures were vaguely described as an "assault" event in the patient chart and 14 (4\%) reported being hit with an unknown object. As seen in Figure 1, the prevalence of intentionally induced facial fractures requiring surgery more than doubled from 2012 to 2017, from 29 to 67 cases. The prevalence of padlock induced facial fractures was also found to increase 2-fold from 2012 to 2017, from 7 to 14 . The prevalence of fist to face injuries is included in the figure for comparison and was also found to increase substantially during our timeframe. As seen in Table 2, in the 57 patients injured by a padlock we recorded 134 total facial fractures with an average of $2.28(\mathrm{SD}=1.33)$ facial fractures per patient. The

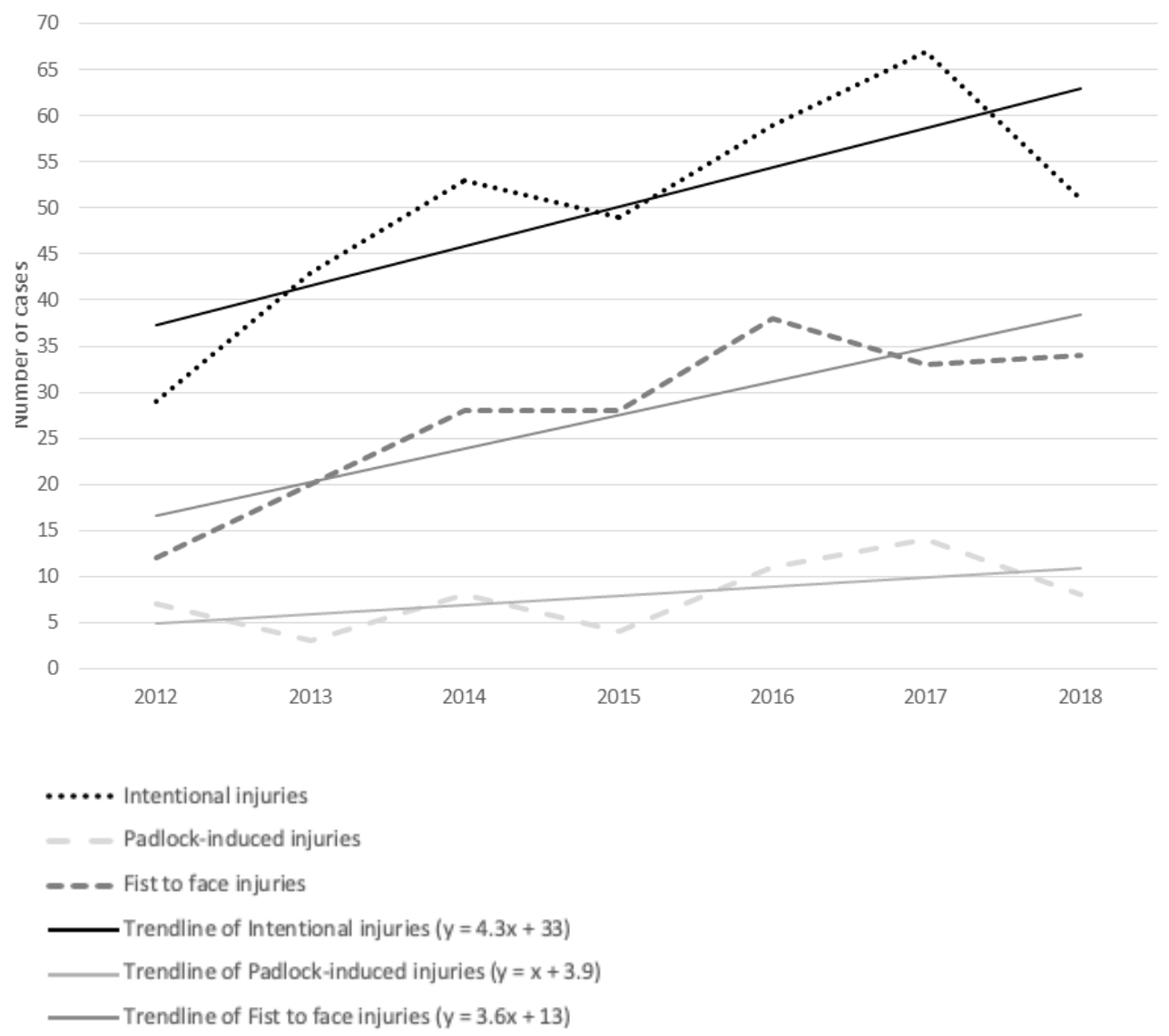

Figure 1: Prevalence of facial fracture by mechanism of injury. This figure depicts the increasing prevalence of facial fracture injuries treated surgically via intentional mechanisms with fist to face and padlock-induced injuries. 
majority of fractures were observed to occur in the mandible (36\%) and orbit (25\%). As seen in Table 3, the most common surgically repaired fracture sites in this same group involved the mandible (53\%), zygomatic arch (15\%) and nasal bone (13\%). As shown in Table 4, a majority of the patients involved in an intentional injury were 16 to 29 years of age. Seventy-five percent of padlock induced facial fractures occurred in patients who were 16 to 39 years of age. $98 \%$ of padlock induced facial fractures occurred in men.

\section{Discussion}

Intentional facial fracture injuries have increased in the Louisiana incarcerated population from 2011-2019. We found the padlock to be the most common cause of facial fracture besides the fist. The mandible is the most common site treated surgically for a padlock-induced injury. Mandibular fractures treated surgically with intermaxillary fixation may require nutritional support for up to six weeks post-operatively [7]. This six week period is associated with airway problems, malnutrition leading to decreased wound healing, and changes in serum potassium levels

Table 2: Anatomical location of padlock-induced fracture. This table illustrates the anatomical locations of facial fractures from 57 cases where a padlock was the reported mechanism of injury.

\begin{tabular}{|c|c|c|}
\hline Anatomical location & Number of fractures $(\mathbf{n}=\mathbf{1 3 4})$ & $\mathbf{\%}$ \\
\hline Mandible & 48 & $36 \%$ \\
\hline Orbit & 33 & $25 \%$ \\
\hline Zygomatic bone & 21 & $16 \%$ \\
\hline Nasal bone & 15 & $11 \%$ \\
\hline Maxilla & 12 & $9 \%$ \\
\hline Alveolar ridge & 3 & $2 \%$ \\
\hline Frontal bone & 2 & $1 \%$ \\
\hline
\end{tabular}

Table 3: Anatomical location of padlock-induced fractures treated surgically. This table illustrates the anatomical locations of facial fractures from 57 cases where a padlock was the reported mechanism of injury and were treated surgically.

\begin{tabular}{|c|c|c|}
\hline Anatomical location & Number of surgeries $(\mathbf{n = 6 8 )}$ & $\mathbf{\%}$ \\
\hline Mandible & 36 & $53 \%$ \\
\hline Zygomatic arch & 10 & $15 \%$ \\
\hline Nasal bone & 9 & $13 \%$ \\
\hline Orbital floor & 6 & $9 \%$ \\
\hline Alveolar ridge & 5 & $7 \%$ \\
\hline Maxilla & 1 & $1 \%$ \\
\hline Frontal sinus & 1 & $1 \%$ \\
\hline
\end{tabular}

Table 4: Age distribution of incarcerated patients (The age distribution of selected mechanisms of injury).

\begin{tabular}{|c|c|c|c|c|}
\hline $\begin{array}{c}\text { Age at } \\
\text { discharge }\end{array}$ & $\begin{array}{c}\text { Unintentional } \\
\text { injuries }(\mathbf{n}=\mathbf{5 7})\end{array}$ & $\begin{array}{c}\text { Intentional injuries } \\
(\mathbf{n}=\mathbf{3 6 6})\end{array}$ & $\begin{array}{c}\text { Fist to face } \\
(\mathbf{n}=\mathbf{2 0 0})\end{array}$ & $\begin{array}{c}\text { Padlock } \\
(\mathbf{n}=\mathbf{5 7})\end{array}$ \\
\hline $16-29$ & 29 & 173 & 110 & 22 \\
\hline $30-39$ & 20 & 112 & 49 & 21 \\
\hline $40-49$ & 5 & 61 & 32 & 11 \\
\hline $50-59$ & 3 & 17 & 7 & 3 \\
\hline $60+$ & 0 & 3 & 2 & 0 \\
\hline
\end{tabular}

that may require special monitoring or electrolyte supplementation. ${ }^{7}$ The post-operative care for these patients requires significant attention and resources from correctional facility staff. Preventing these types of injuries may help to reduce the burden placed on the correctional facility. The reliance on patient reported mechanisms of injury is a limitation to the study design. In 119 (27\%) reviewed cases, we found that the selfreported mechanism of injury did not correlate with the severity of the injury. A common example included a patient reporting a fall in the shower with bilateral mandible fractures. We feel that injuries by intentional mechanisms are under reported with fear of retaliation from prison staff or inmates after returning to the correctional facility. We hope to contribute to better control of the commissary padlock supply or a built-in lock mechanism for lockers available to inmates to reduce the burden and severity of facial trauma. Future aims include analyzing the cost to society for treatment of padlock and 'slock' induced facial fractures.

\section{Conclusion}

Padlock induced injuries are the most common cause of facial fracture in incarcerated patients besides the fist. The prevalence of 'slock'-induced facial fractures appears to be increasing in the Louisiana incarcerated population from 2011-2019. The mandible is the most common site treated surgically for padlock-induced fracture. Stricter regulations on the padlock supply may reduce the prevalence of facial fractures in this setting. Future studies should analyze the costs to society for treatment and the potential for an alternative from providing padlocks to inmates.

\section{Conflict of Interest}

The authors declare no conflict of interest.

\section{Institutional Review Board}

The study was judged exempt from review by the institutional review board.

\section{Acknowledgement}

This research did not receive any specific grant from funding agencies in the public, commercial, or not-for-profit sectors.

Triological Society Combined Sections Meeting Poster Presentation, Coronado, California, USA, January 23-25, 2020.

\section{References}

1. Bronson J, Carson EA (2019) Prisoners in 2017. U.S. Department of Justice, Bureau of Justice Statistics.

2. Wagner P, Sawyer W (2018) States of incarceration: the global context 2018. Prison Policy Initiative.

3. Safety in custody statistics bulletin, England and Wales, deaths in prison custody to December 2018, assaults and self-harm to September 2018. Ministry of Justice 2019.

4. Kuzak N, O'Connor M, Pickett W, O'Brien T, Reid K, Pearson M (2001) Impact of a prison triage system on injuries seen in emergency departments. Canadian Journal of Emergency Medicine 3: 199-204.

5. Henning J, Frangos S, Simon R, Pachter HL, Bholat OS (2015) Patterns of traumatic injury in New York City prisoners requiring hospital admission. Journal of Correctional Health Care 21: 53-58. 
Cherie-Ann O. Nathan (2020) Assessment of Facial Injury by 'Slock' in Incarcerated Patients

6. Lincoln JM, Chen LH, Mair JS, Biermann PJ, Baker SP (2006) Inmate-made weapons in prison facilities: assessing the injury risk. Journal of the International Society for Child and Adolescent Injury Prevention 12: 195-198.
7. Giridhar VU (2016) Role of nutrition in oral and maxillofacial surgery patients. National Journal of Maxillofacial Surgery 7: 3-9.

\section{Citation:}

Charles Dodge Rees, Adam Blancher, Paige Bundrick, Mickie Hamiter, Tara Moore-Medlin, et al. (2020) Assessment of Facial Injury by 'Slock' in Incarcerated Patients. Otorhinolaryngol Hypersensitivity Treat Volume 1(2): 1-4. 